London, UK

jane@janefeinmann.com

Cite this as: BMJ2020;371:m4585 http://dx.doi.org/10.1136/bmj.m4585 Published: 30 November 2020

\section{When the masks don't fit: the British collaboration making PPE designed for individuals}

\begin{abstract}
With research suggesting that one in four doctors believes their personal protective equipment is unsafe, Jane Feinmann reports on a UK collaboration that is developing effective facial protection for clinicians
\end{abstract}

\section{Jane Feinmann}

The supply of personal protective equipment (PPE) has been a headline generating problem from the start of the covid-19 pandemic. But for doctors, even if they can get hold of it, an additional concern is whether protective masks are both wearable and safe, most notably for clinicians carrying out aerosol generating procedures. Now, a collaboration of doctors, engineers, and imaging specialists is showing that a one-size-fits-all approach to PPE fails to protect clinicians with smaller, larger, or flatter faces-particularly women and those from black and minority ethnic (BAME) backgrounds-and are tackling the problem with personalised PPE prescriptions.

Research into doctors' views of their $\mathrm{FFP}_{3}$ masks, to be published soon, shows that one in four clinicians believes they are unsafe either when they are put on or during a long shift. The findings, from a newly formed collaboration between the University of Cambridge, Cambridge University Hospitals (CUH), and led by the Cambridge based Centre for Engineering Better Care, is leading to a system of safe facial PPE that the collaboration aims to launch in early 2021.

A pioneer of this approach, maxillofacial surgery trainee Ambika Chadha, gained first hand experience of the limitations of protective masks as a senior registrar at Addenbrooke's Hospital in the early days of the pandemic. "From the start, I struggled with equipment designed for use in an industrial environment," she says. "The masks weren't a great fit and they muffled voices. I couldn't wear a visor as well as my loupes and headlamp, so surgery took longer and was a lot more tiring."

It soon became clear she wasn't alone-and that the "fit test" for $\mathrm{FFP}_{3}$ respirators introduced throughout the NHS in March 2020 was failing to tackle the problem.

"Feedback from staff using FFP3 respirators made it obvious that we needed to think differently about how we protect those working in high intensity clinical environments," says Kanwalraj Moar, divisional director for women's and children's services and a cleft surgeon at Addenbrooke's Hospital.

\section{Neither personal nor protective}

The BMA has warned of the limitations of one-size-fits-all FFP3 masks. "PPE is too often neither personal nor protective for women," says Helen Fidler, deputy chair of the BMA UK Consultants
Committee, warning that "hundreds of women doctors have told a BMA survey that they failed their 'fit test' for protective masks." "One female friend even apologised for having a 'small, funny face'," she said.

Concern that badly fitting masks contributed to the high rate of deaths from covid-19 among BAME doctors in the $\mathrm{NHS}^{2}$-with this group accounting for 95\% of doctors who died in March and April 2020 while making up just $44 \%$ of the medical workforce ${ }^{3}$ - was acknowledged in a leaked NHS England improvement plan ${ }^{4}$ to be linked to facial shape, including smaller, larger, or flatter faces. It meant "some BAME health workers having failed fit tests for masks and in these cases NHS trusts should certify and redeploy them."

Against this background, a conversation between Moar and Chadha in April set in motion the multidisciplinary collaboration. "We talked about a plan to use imaging technology to confront the problem of poorly fitting masks-including the fact that masks can fit when the face is static but are at risk of leaking as soon as the practitioner starts to talk or move their face," says Chadha.

They weren't alone: in April, social media were buzzing with similar proposals from small research groups and industrial hubs. Chadha's ongoing doctorate has involved several years of research including with Cambridge based Cleft Net East, one of 10 national tertiary cleft networks of excellence, in developing both $3 \mathrm{D}$ (static) and, significantly, $4 \mathrm{D}$ (dynamic) photographic imaging to evaluate outcomes in cleft lip surgery work. Addenbrooke's also had access to the Cambridge Biomedical Campus, the largest centre of medical research and health science in Europe.

By May, a multidisciplinary team, now 25 strong, had assembled with specialist groups in virology, clinical, and systems engineering, imaging, and $3 \mathrm{D}$ printing - "all of them world class in their field," says Chadha, who was released from clinical duties to work on the project full time. The team was co-led by Moar and John Clarkson, professor of engineering design at the University of Cambridge and author of the newly published toolkit Improving Improvement, ${ }^{5}$ which spells out a methodical systems approach to redesign in healthcare.

\section{Sustainable PPE}

For three months, Clarkson questioned members of surgical teams about their work at the beginning of 
each day for an hour. "It was vital to understand the sequence of tasks required of each member of the clinical team," he explains. "There's no point in a brilliant innovation that takes no account of how clinical teams actually work." Chadha's interview took seven hours. "Until then I'd always thought my job was straightforward," she says.

The "granular" survey of clinicians' experience of PPE was meticulously planned and gained widespread professional support, including being nested within the covid-19 research portfolio of the Royal College of Surgeons. The findings, based on 1600 complete responses and a further 2000 comments, has confirmed concerns about facial shapes. The responses have also highlighted the lack of standardisation of the many different brands of masks in use: "I counted 45 brands named by clinicians," says Chadha.

The collaboration's proposed solution is to hand responsibility for fitting masks to hospital occupational health departments. "Every NHS employee will have their own 3D and 4D 'selfie' which will be combined with data produced by an evidence based algorithm that can stratify each person's risk of acquiring covid-19 infection during work related activity,” explains Clarkson. “That will provide a prescription for an appropriate mask similar to the prescription already used for surgical loupes.”

For those with low risk jobs or a conventional facial shape, PPE can be off the shelf. Others will require customised masks, identified for a single person's use.

From early 2021, the team will "explore the process of matching people to existing masks with CUH staff," explains Clarkson. “The insights gained will inform current mask manufacturers of the range of sizes that could better fit the user population, leading to rapid improvements in the range of off the shelf masks," he says.

At the same time, the work with CUH staff will identify the need for bespoke masks for particular people and particular activities, alongside a programme of work that will map the process of individualised mask delivery.

Sustainability is another key aspect of the project. The team is in negotiation with Invisi Smart Technologies, a British biotechnology company that has developed a new, light activated virucidal coating with proved activity against covid-19. "It means the mask, and PPE generally, can be decontaminated by placing them in a light box for a period of time, eventually perhaps ending the need for disposable PPE,” says Clarkson.

The collaboration is currently negotiating external funding for the research study while the funding for product and process development is likely to be taken on by the biotechnology partner-with the aim of delivering safer mask design and production as speedily as possible. The problem is that with hospitals under renewed pressure from covid-19 admissions, the bespoke mask design process is likely to take up to two years to reach a global market, says Clarkson. "Of course, we want to get this system up and running as soon as possible. But it's got to work for everyone and is too important for shortcuts," says Chadha.

Provenance and peer review: Commissioned, not externally peer reviewed.

Competing interests: None declared.

BMA. In harm's way. 11 May 2020. www.bma.org.uk/news-and-opinion/in-harm-s-way. Pugh R. Covid-19 PPE gender divide: no one-size-fits-all? Medscape. 4 May 2020. www.medscape.com/viewarticle/929860.

3 BMA. Covid-19: the risk to BAME doctors. 13 November 2020. www.bma.org.uk/advice-andsupport/covid-19/your-health/covid-19-the-risk-to-bame-doctors.
4 Kituno N. Revealed: the NHS' plan to protect BAME staff from covid-19. 6 May 2020. www.hsj.co.uk/workforce/revealed-the-nhs-plan-to-protect-bame-staff-from-covid19/7027571.article.

5 Improving improvement. https://q.health.org.uk/idea/2019/improving-improvement. 